\title{
PENGEMBANGAN PRODUK KOPI HERBAL OLAHAN DESA INKLUSIF GUNA MENINGKATKAN KESEJAHTERAAN KAUM DISABILITAS DI DESA BEDALI LAWANG KABUPATEN MALANG
}

\author{
Mochamad Fariz (rianto1), Supami Wahyu Setiyowati ${ }^{1)}$, Shodiq Auludin Rafiqu Hidayah¹) \\ 1)Program Studi Akuntansi, Fakultas Ekonomika Dan Bisnis, Universitas Kanjuruhan, Malang, Jawa Timur, Indonesia \\ Corresponding author : Mochamad Fariz Irianto \\ E-mail : mochamadfarizirianto@unikama.ac.id
}

Diterima 7 November 2020, Direvisi 16 November 2020, Disetujui 16 November 2020

\begin{abstract}
ABSTRAK
Pengembangan produk kopi herbal merupakan bagian dari pemberdayaan masyarakat dalam bentuk kegiatan produktif yang bertujuan untuk melatih masyarakat disabilitas untuk menghasilkan produk kopi herbal yaitu kopi koerja yang diharapkan memberikan dampak pada peningkatan kesejahteraan masyarakat. Metode pelaksanaan yang dilakukan adalah dengan sosialisasi program, pengadaan mesin dan pengadaan bahan penunjang, pelatihan pengolahan produk kopi herbal, dan pelatihan pemasaran strategi produk. Kegiatan ini diikuti oleh kelompok sasaran yaitu masyarakat disabilitas yang tergabung dalam organisasi difabel Lingkar Sosial Omah Difabel dengan peserta sebanyak 10 orang. Pelatihan ini sangat dirasakan manfaatnya oleh para peserta pelatihan anggota disabilitas seperti kemudahan pengoperasian alat produksi, rebranding produk, dan peningkatan jaringan pemasaran produk.
\end{abstract}

Kata kunci: kopi herbal; masyarakat disabilitas; desa inklusif.

\begin{abstract}
The development of herbal coffee products is part of community empowerment in the form of productive activities that aim to train people with disabilities to produce herbal coffee products namely koerja coffee which is expected to have an impact on improving people's well-being. The implementation method is by socializing the program, procurement of machinery and procurement of supporting materials, training in processing herbal coffee products, and marketing training of product strategies. This activity was attended by a target group, namely people with disabilities who belonged to the Omah Difabel Social Circle disability organization with 10 participants. This training is strongly felt by the participants of disability member training such as ease of operation of production tools, product rebranding, and improvement of product marketing network
\end{abstract}

Keywords: herbal coffee; people with disabilities; inclusive villages.

\section{PENDAHULUAN}

Masyarakat disabilitas merupakan orang yang mengalami keterbatasan fisik, intelektual, mental, dan/atau sensorik dalam jangka waktu lama yang dalam berinteraksi dengan lingkungan dapat mengalami hambatan dan kesulitan untuk berpartisipasi secara penuh dan efektif dengan warga negara lainnya berdasarkan kesamaan hak (Indonesia, 2016). Dalam kondisi nyata, banyak masyarakat disabilitas yang tidak mendapat pemenuhan terhadap haknya serta kesetaraan dengan masyarakat umum lainnya.

Dengan adanya kondisi tersebut, masyarakat penyandang disabilitas layak untuk mendapatkan perhatian lebih dalam penyetaraan status sosial. Sejak muncul wabah pandemi COVID-19 tidak hanya menyerang masalah kesehatan namun juga masalah ekonomi, semakin membuat kondisi perekonomian menurun yang mengakibatkan penurunan pendapatan termasuk masyarakat disabilitas (Abdul Aziz, 2020) (Salsabela Nur Fauzia, 2020). Menurut (Thaha, 2020) usaha kecil dan menengah (UMKM) berada di garis depan guncangan ekonomi yang disebabkan oleh pandemi COVID-19. Langkah-langkah penguncian (lockdown) telah menghentikan aktivitas ekonomi secara tiba - tiba, dengan penurunan permintaan dan mengganggu rantai pasokan di seluruh dunia. Untuk meningkatkan kesejahteraan masyarakat disabilitas, perlu adanya pemberdayaan masyarakat dalam bentuk kegiatan usaha produktif. Kegiatan usaha produktif dapat membantu meningkatkan perekonomian sehingga kesejahteraan masyarakat dapat terangkat (Nugraha, Fauzi, \& Ekayani, 2019). 
Desa Bedali telah ditetapkan sebagai Desa Inkusif oleh pemerintah desa setempat sejak tahun 2019. Desa Inklusif merupakan program untuk memastikan peran aktif dan keterlibatan semua pihak termasuk penyandang disabilitas dalam proses pembangunan di tingkat desa/kelurahan.

Masyarakat disabilitas yang ada di

Desa Bedali melakukan beberapa kegiatan usaha produksi kopi. Kegiatan usaha produksi kopi yang dijalankan oleh masyarakat disabilitas masih dalam tahap awal dengan proses yang cukup sederhana. Pengolahan kopi yang dilakukan oleh penyandang disabilitas dapat menjadi potensi yang besar dalam mendongkrak perekonomian dan meningkatkan kesejahteraan masyarakat sasaran apabila dilakukan pengembangan secara tepat. Produk kopi yang dihasilkan masih terbatas kopi bubuk murni dengan pengemasan yang sederhana. Proses pemasaran masih belum berkembang, hanya dalam lingkup internal. Berikut adalah hasil pemetaan permasalahan dan analisa situasi kegiatan produksi masyarakat disabilitas yaitu sebagai berikut :

Tabel 1. Pemetaan Permasalahan dan Analisis Situasi

\begin{tabular}{|c|c|}
\hline Permasalahan & Solusi \\
\hline $\begin{array}{l}\text { Tidak adanya } \\
\text { pengembangan } \\
\text { produk }\end{array}$ & $\begin{array}{l}\text { Pengembangkan } \\
\text { produk kopi herbal } \\
\text { dengan } \\
\text { meningkatkan value } \\
\text { added produk, } \\
\text { modifikasi } \\
\text { pengemasan, hingga } \\
\text { peningkatan kualitas } \\
\text { produk }\end{array}$ \\
\hline $\begin{array}{l}\text { Kualitas sumber } \\
\text { daya manusia yang } \\
\text { rendah }\end{array}$ & $\begin{array}{lr}\text { Sosialisasi, } & \text { edukasi, } \\
\text { pelatihan, } & \text { hingga } \\
\text { pembinaan } & \end{array}$ \\
\hline $\begin{array}{lr}\text { Kurangnya } & \text { alat } \\
\text { produksi } & \text { yang } \\
\text { memadai } & \end{array}$ & $\begin{array}{l}\text { Memberi bantuan } \\
\text { peralatan modern } \\
\text { yang dibutuhkan }\end{array}$ \\
\hline $\begin{array}{l}\text { Lingkup pemasaran } \\
\text { yang sempit }\end{array}$ & $\begin{array}{l}\text { Pelatihan dan } \\
\text { pembimbingan } \\
\text { pemasaran produk } \\
\text { terutama dengan } \\
\text { menggunakan media } \\
\text { online }\end{array}$ \\
\hline
\end{tabular}

Dalam upaya untuk meningkatkan kualitas produk kopi dan memberikan manfaat untuk pengguna maka kopi olahan masyarakat disabilitas dicampur dengan bahan herbal yaitu jahe merah. Secara umum, jahe memiliki kandungan zat gizi dan senyawa kimia aktif yang berfungsi preventif dan kuratif (Aryanta, 2019). Produk kopi herbal ini menjadi sebuah solusi bagi masyarakat untuk meningkatkan imunitas tubuh sebagai upaya menghadapi pandemi Covid-19. Karena pada masa pandemi ini, salah satu produk yang mengalami peningkatan permintaan yaitu produk yang bermanfaat bagi kesehatan (Yenti Sumarni, 2020).

Pengusul berfokus pada pengembangan olahan kopi herbal. Mulai dari segi value added produk dalam proses produksi dengan menggunakan alat - alat modern hingga strategi pemasaran online. Dalam hal ini dibutuhkan keterlibatan para penyandang disabilitas untuk memproduksi kopi herbal, agar bisa produktif dan mandiri. Hal tersebut akan berdampak pada peningkatan ekonomi untuk mencapai kesejahteraan masyarakat disabilitas. Dengan adanya pengembangan tersebut, diharapkan produk olahan kopi herbal memiliki nilai jual tinggi dan target pemasaran menjadi lebih luas. Untuk mendukung pengembangan olahan kopi herbal, diperlukan kelengkapan alat produksi kopi yang lebih canggih serta mudah dioperasikan para penyandang disabilitas, serta sosialisasi dan pembinaan mengenai penerapan strategi dan metode yang tepat dalam produk kopi herbal.

\section{METODE}

Dalam metode pelaksanaan ini ada beberapa tahapan yang dilalui berdasarkan pemetaan permasalahan dan analisa situasi pada masyarakat disabilitas di Desa Bedali, Kecamatan Lawang Kabupaten Malang. Pelaksanaan kegiatan ini dilakukan sejak bulan September 2020 sampai dengan bulan November 2020 dengan kelompok sasaran yaitu masyarakat disabilitas yang tergabung dalam organisasi difabel Lingkar Sosial Omah Difabel. Kegiatan ini diikuti oleh sebanyak 10 orang dari anggota lingkar sosial omah difabel. Pada rancangan awal kegiatan dilakukan survei dan observasi atas kegiatan usaha produksi kopi masyarakat disabilitas selanjutnya dilakukan identifikasi masalah dan analisa kebutuhan.

Adapun tahapan pelaksanaan kegiatan pengembangan olahan kopi herbal dapat dilihat pada Gambar 1, dengan penjabaran sebagai berikut :

1. Tahap Sosialisasi Program

Pada tahap ini, akan diadakan sosialisasi tentang beberapa kegiatan yang menjadi progran Bina Desa. Masyarakat sasaran kaum disabilitas dikumpulkan dan diberikan pemahaman tentang peningkatan pendapatan dengan produksi kopi herbal serta akan dilakukan demonstrasi dalam pembuatan produk 
2. Tahap Pengadaan Mesin dan Pengadaan Bahan Penunjang

Pengadaan alat atau mesin produksi untuk proses pengolahan biji kopi dan bahan herbal untuk menjadi produk kopi herbal. Dalam pengadaan mesin ini juga akan memudahkan kaum disabilitas dalam proses produksi untuk menunjang efisiensi waktu kuantitas dan kuantitas produksi

3. Pelatihan Pengolahan Produk Kopi Herbal Dilakukan pelatihan dan pendampingan cara menggunakan alat atau mesin produksi untuk proses pengolahan biji kopi dan bahan herbal untuk menjadi produk kopi herbal. Kaum disabilitas diberikan pengarahan mulai dari pembuatan produk sampai pada pengemasan produk.

4. Pelatihan Strategi Pemasaran Produk Memberikan sosialisasi dan edukasi yang tepat terutama melalui media online agar menjaga segmentasi pasar untuk menjangkau wilayah yang lebih luas dalam memasarkan produk kopi secara langsung ataupun sosial media dengan harga yang lebih tinggi dari sebelumnya

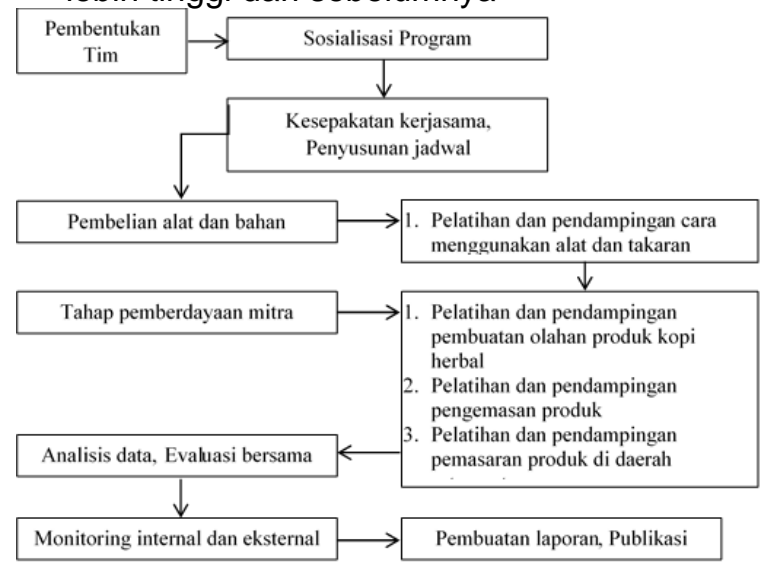

Gambar 1. Tahapan Pelaksanaan

\section{HASIL DAN PEMBAHASAN}

Dalam pelaksanaan kegiatan ditengah pandemi COVID-19 tetap melakukan protokoler kesehatan memakai masker dan cuci tangan atau pemberian handsanitizier.

Pembukaan sekaligus peresmian Kegiatan PHP2D berlokasi di Balai Desa Bedali Kecamatan Lawang, Kabupaten Malang pada tanggal 17 September 2020 yang dihadiri oleh sebanyak 30 orang yaitu Dinas Kesehatan Kabupaten Malang, Dinas Koperasi dan Usaha Mikro Kabupaten Malang, Kepala Desa Bedali, Babinsa Babikamtibnas Desa Bedali, Ketua Lingkar Sosial Malang beserta kadernya, Dekan dan Dosen di lingkungan Fakultas Ekonomika dan Bisnis Universitas Kanjuruhan Malang serta masyarakat disabilitas. Dalam kegiatan sosialisasi awal diberikan pemaparan terkait program kerja yang akan dilakukan mulai dari tahap analisa permasalahan, indikator ketercapaian usaha, tahapan kegiatan sampai dengan evaluasi kegiatan. Dengan adanya pemaparan tersebut diharapkan semua pihak pihak terkait bisa mendukung pelaksanaan kegiatan mulai dari perijinan kegiatan sampai dengan tahap evaluasi pelaksanaan kegiatan.

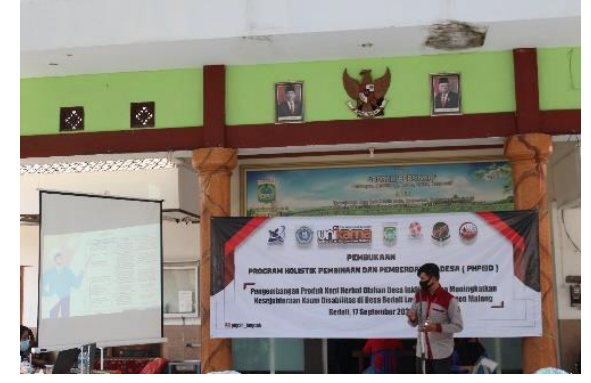

Gambar 2. Sosialisasi Program

Pada kesempatan tersebut juga dilakukan penyerahan peralatan mesin giling kopi dan jahe kepada ketua lingkar sosial omah difabel yaitu bapak Ken Kertaningtyas yang nanti selanjutnya akan dimanfaatkan oleh para anggota atau kader lingkar sosial omah difabel dalam memproduksi kopi herbal. Untuk peralatan penunjang lainnya dilaksanakan dan diserahkan secara bertahap kepada lingkar sosial omah difabel.

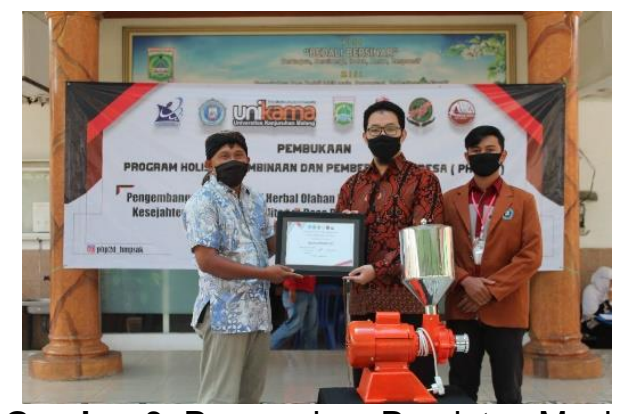

Gambar 3. Penyerahan Peralatan Mesin Giling Kopi dan Jahe

Selama periode bulan september 2020 sampai dengan november 2020 dilakukan pelatihan dan pendampingan cara menggunakan alat atau mesin produksi untuk proses pengolahan biji kopi dan bahan herbal untuk menjadi produk kopi herbal. Tahapan pelaksanaan produksi kopi herbal adalah sebagai berikut :

1. Persiapan bahan berupa biji kopi, jahe merah dan gula merah

2. Persiapan peralatan produksi dan peralatan penunjang

3. Pengeringan bahan baku jahe merah

4. Penggilingan biji kopi dan jahe merah yang sudah kering

5. Penakaran komposisi hasil giling biji kopi dan jahe merah 
6. Pengemasan produk kopi herbal

7. Produk kopi herbal siap dipasarkan

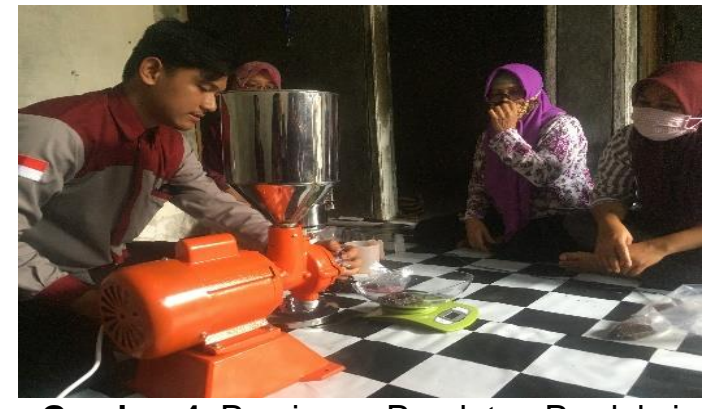

Gambar 4. Persiapan Peralatan Produksi

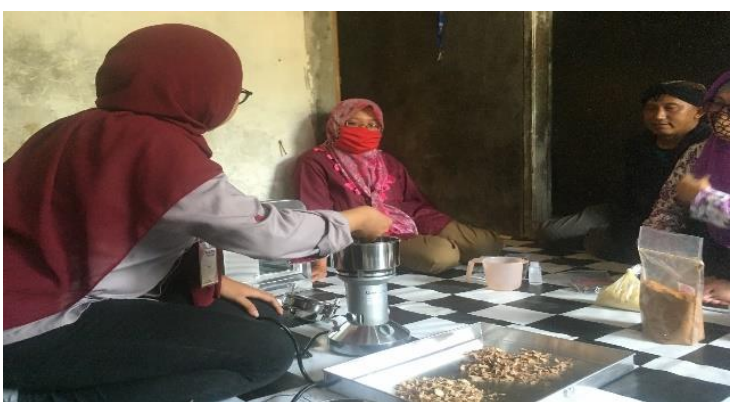

Gambar 5. Pengeringan Bahan Baku Jahe Merah

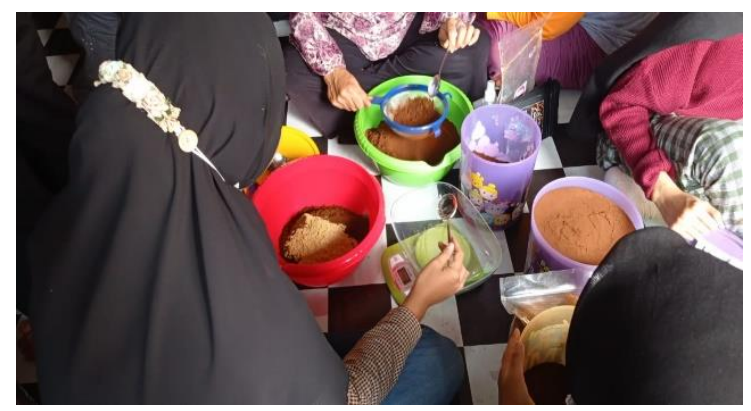

Gambar 6. Penakaran komposisi kopi dan jahe merah

Hasil dari penakaran komposisi jahe merah dan kopi dimasukkan dalam kemasan alumunium foil yang bertujuan untuk menjaga produk agar lebih tahan lama. Produk yang sudah dikemas diberi label dengan brand baru yaitu brand Kopi Koerja.

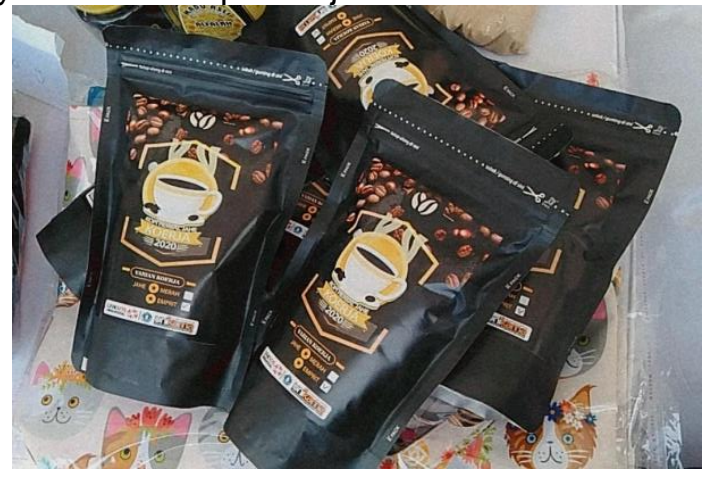

Gambar 7. Kopi Koerja
Tahapan selanjutnya adalah proses pemasaran yang dilakukan baik pemasaran secara online maupun pemasaran secara offline. Pemasaran secara online dilakukan untuk memperluas jaringan pasar penjualan produk kopi herbal tidak terbatas hanya di daerah tertentu atau kawasan tertentu namun menjangkau ke seluruh nusantara. Hal ini dilakukan selain memperluas jaringan pemasaran juga untuk meningkatkan total penjualan yang berimbas pada peningkatan keuntungan usaha (Setiawati \& Widyartati, 2017). Pemasaran secara online ini dilakukan dengan memanfaatkan website khusus produk malang lingkar sosial yaitu menggunakan website berbayar yaitu orderonline.id

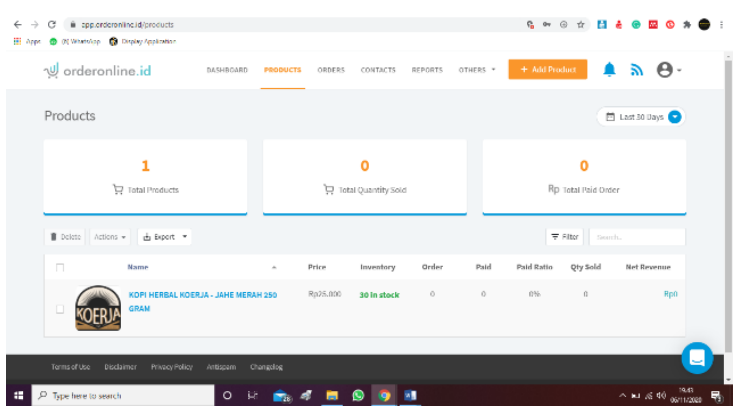

Gambar 8. Website Kopi Herbal Kopi Koerja

Untuk pemasaran secara offline dilakukan dengan pemasaran di berbagai kegiatan seperti pemasaran di kegiatan pameran baik tingkat kota maupun kabupaten malang. Selain itu dilakukan penitipan produk kopi dengan sistem konsinyasi di beberapa toko di kabupaten malang.

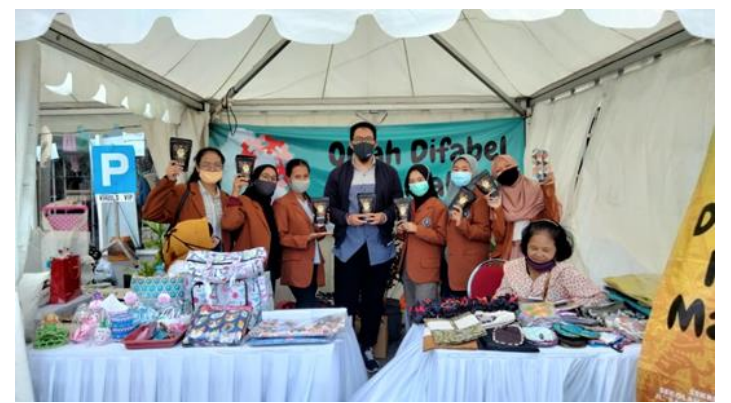

Gambar 9. Pameran Produk Kopi Herbal Kopi Koerja

Pelatihan ini sangat dirasakan manfaatnya oleh para peserta pelatihan anggota disabilitas seperti kemudahan pengoperasian alat yang tidak memerlukan keahlian khusus dan sudah dilengkapi panduan pengguna baik berupa buku panduan maupun video panduan yang dibuat oleh pengusul. Kemudahan proses produksi menggunakan teknologi tepat guna untuk mencapai hasil yang maksimal. Rebranding produk kopi baik dari segi kemasan (packaging) maupun dari logo 
produk yang eyecatching sehingga meningkatkan brand awareness di kalangan konsumen (Nastain, 2017). Manfaat lain dari pelatihan ini adalah proses pemasaran yang tepat didukung dengan teknologi terkini diharapkan dapat memperluas jaringan pemasaran yang selama ini masih sebatas pemasaran internal organisasi.

\section{SIMPULAN DAN SARAN}

Wabah pandemi COVID-19 tidak hanya menyerang masalah kesehatan namun juga masalah ekonomi, ditandai dengan kondisi perekonomian masyarakat yang semakin menurun termasuk masyarakat disabilitas. Solusi atas kondisi permasalahan yang ada adalah peran aktif seluruh lapisan masyarakat termasuk peran dari akademisi. Kegiatan pelatihan yang dilakukan oleh para akademisi memberikan dampak positif ditengah keterbatasan yang ada. Pola kerjasama ini diharapkan dapat bersama - sama melawan pandemi COVID - 19 oleh seluruh lapisan masyarakat. Dampak atas pelatihan tersebut adalah peserta mampu dengan mudah mengoperasikan peralatan, proses pengemasan produk yang menarik hingga proses pemasaran yang tepat dengan jangkaun yang lebih luas.

\section{UCAPAN TERIMAKASIH}

Terima kasih kepada Direktorat Pembelajaran dan Kemahasiswaan, Direktorat Jenderal Pendidikan Tinggi Kementerian Pendidikan dan Kebudayaan yang telah mendanai kegiatan ini dengan dana Program Holistik Pembinaan dan Pemberdayaan Desa (PHP2D) tahun anggaran 2020.

\section{DAFTAR RUJUKAN}

Abdul Aziz. (2020). Dampak Negatif yang Dialami Difabel Selama Pandemi COVID19 - Tirto.ID. Retrieved November 7, 2020, from https://tirto.id/dampak-negatif-yangdialami-difabel-selama-pandemi-covid19-fGi1

Aryanta, I. W. R. (2019). Manfaat Jahe Untuk Kesehatan. Widya Kesehatan, 1(2), 3943.

Indonesia, P. R. (2016). UU Nomor 8 Tahun 2016. Jakarta: Undang Undang Republik Indonesia.

Nastain, M. (2017). Branding dan eksistensi produk (kajian teoritik konsep branding dan tantangan eksistensi produk). CHANNEL, Universitas Mercu Buana Yogyakarta, 5, 14-26.

Nugraha, R. P., Fauzi, A., \& Ekayani, M. (2019). Ekonomi Pertanian, Sumberdaya Dan Lingkungan ( Journal of Agriculture ,
Resource , and Environmental Economics ) Analisis Pendapatan Usaha Pertanian dan Peternakan. Jurnal Ekonomi Pertanian, Sumberdaya Dan Lingkungan, 2, 1-14.

Salsabela Nur Fauzia. (2020). Kesejahteraan Sosial Pada Masa Pandemi Covid-19: Apa Kabar Kesejahteraan Penyandang Disabilitas? | Puspensos. Retrieved November 7, 2020, from https://puspensos.kemsos.go.id/kesejaht eraan-sosial-pada-masa-pandemi-covid19-apa-kabar-kesejahteraanpenyandang-disabilitas

Setiawati, I., \& Widyartati, P. (2017). Pengaruh Strategi Pemasaran Online Terhadap Peningkatan Laba UMKM. In PROCEEDINGS (Vol. 1).

Thaha, A. F. (2020). Dampak Covid-19 Terhadap UMKM di Indonesia. Jurnal Brand, 2(1), 147-153.

Yenti Sumarni. (2020). Pandemi Covid-19: Tantangan Ekonomi Dan Bisnis. Jurnal Ekonomi Dan Perbankan Syariah, 6(2), 46-58. 